\title{
Comment on the letter to the editors from Thomas Läubli
}

\author{
Dr. Jenkins is a post-doctoral research fellow and Dr. Fultz is a research investigator in the Survey Research Center \\ of the Institute for Social Research at the University of Michigan. Dr. Fonda is an instructor at Harvard Medical School \\ and a research investigator at Joslin Diabetes Center in Boston, MA. Dr. Wray is an assistant professor of biobehavioral \\ health at the Pennsylvania State University in University Park, PA
}

Dear editors,

We would like to address the concerns that Dr. Läubli presented in his letter to the editors pertaining to our article "Patterns of body weight among middle-aged and older Americans, by gender and race, 1993-2000”. First, we thank him for making the valid point that race may be correlated with other factors, such as socio-economic status, that contribute to patterns of body weight. We also think it is worthwhile to note that differences between men's and women's body weight patterns are also likely to reflect numerous underlying factors. Second, we want to clarify that our article is descriptive. We are not suggesting any causal order from our analyses or interpretation. Our primary reason for examining the association between race and body weight in these analyses was because of the lack of longitudinal data for minority groups, where obesity is a particular problem (please see Lee et al. 2001 for further discussion). We are simply stating in the article that the relationship between race and body weight is very complex and, as also noted by Dr. Läubli, that further research is needed to more effectively target areas for intervention.

Kristi R. Jenkins, Nancy H. Fultz, Stephanie J. Fonda and Linda A. Wray

\section{References}

Jenkins KR, Fultz NH, Fonda SJ, Wray LA (2003). Patterns of body weight among middleaged and older Americans, by gender and race, 1993-2000. Soz Praventiv Med 48: 257-68.
Lee I-M, Blair S, Allison D, Folsom A, Harris T, Manson J, Wing R (2001). Epidemiologic data on the relationships of caloric intake, energy balance, and weight gain over the life span with longevity and morbidity. J Gerontol A Biol Sci Med Sci 56A (Special Issue 1): 7-19.

\section{Address for correspondence}

Kristi Rahrig Jenkins, PhD Institute for Social Research University of Michigan 426 Thompson St., Room \#2044 USA-Ann Arbor, MI 48106 Tel.: +1 7347633221 E-mail: Kristirj@isr.umich.edu 